\title{
Capitals, Ethnic Identity and Educational Qualifications
}

Tariq Modood

Cultural capital analysis, or class analysis more generally, exacerbates rather than resolves the anomaly of why non-white ethnic minorities in Britain are over-represented in higher education. Some of these groups have a disproportionate lower, socio-economic profile and yet at least some of these groups are more likely to pursue and achieve entry into higher education than whites, especially, their white working-class peers. They also suffer additional disadvantages such as racism and cultural marginality. Bourdieu's concept of cultural capital is designed to explain why members of a disadvantaged class achieve less educational success than an advantaged class. It is not helpful in explaining why some disadvantaged groups do better than one would have predicted on the basis of a class (and/or racism) analysis. On the other hand, US sociological studies which deploy the concept of social capital in combination with ethnicity to explain the trajectories of 'second generation' migrants seem promising. This conclusion is offered on the basis of a brief literature review and a suggestion that the 'motor' of the British South Asian and Chinese overcoming of disadvantage lies in migrant parents getting their children to internalize high educational ambitions and to enforce appropriate behaviour.

Keywords: Cultural capital; Social capital; Ethnicity; Educational qualifications; Second generation; Social mobility

\section{Introduction}

Savage, Warde and Devine (2004) argue that if we accept the shift in definition of class as macro-relationships such as exploitation to the possession of resources by individual actors, as many sociologists have done, then an argument can be made for the importance of concepts like cultural capital. They argue: 'If social class is a matter of categories of people accumulating similar volumes and types of resources, and investing them in promoting their own and their children's life chances, the metaphor of capital is helpful' (2003, p. 7). This conception of social class as a likelihood of members' achieving 
certain socio-economic goals (for example, sustaining a position in or entering certain kinds of occupations) is helpful. The idea of class as life-chances means that the definition of a class system depends not just on the existence of a hierarchy of classes but on the probabilities of movement between classes. The metaphorical extension of the idea of capital beyond the financial is also helpful, However, the argument here will be that both class and a Bourdieuian concept of cultural capital have certain important limitations in that neither of them are able to deal sociologically with some contemporary ethnic phenomena in relation to resources, capital and the likelihood of mobility.

This article arises in the context where, amongst sociologists, class is seen to be a much more substantial concept than ethnicity (see, for example, Fenton, 1999, 2003); where the influence of Bourdieu in the sociology of education is immense (Reay, 2004) and is believed to be transferable to ethnicity studies (May, 1999); and where the concept of cultural capital is enjoying a currency and an expectancy amongst those who believe that cultural pursuits have something to contribute to the amelioration of social exclusion. These positions will be challenged by focusing on a major empirical question: why are non-white ethnic minorities in Britain so over-represented in applications to and amongst students in higher education? The fact that they are is so counter-intuitive that while British sociologists have developed several lines of inquiry to explain the scholastic under-achievement of non-whites (a phenomenon that has failed to occur, except in pockets) there are no theories to explain the phenomenon that has occurred. Initially, it might be expected that this phenomenon-for it is about the acquisition of credentials for upward mobility in a stratified society, and after all, ethnicity is something to do with 'culture'-might be most amenable to a cultural capital class analysis. The article will show that this expectation cannot be fulfilled. Instead, it will be suggested that a version of or a derivation of the idea of social capital is more promising. The promise can be redeemed by studying some American sociology in which the Bourdieuian distinction between cultural capital, which is acquired through the family, and social capital as benefits mediated through social relations is not maintained; indeed the former is swallowed up within the latter. An older influence on the thinking in this article comes from an approach in British anthropology that was sometimes called 'ethnicity as a resource' (for example, Ballard, 1996; Wallman, 1979; Werbner, 1990a, 1990b), although their interest was more in employment, especially self-employment.

Besides the sociological puzzle there is also a practical concern. Broadly, how to achieve a society in Britain that is not racially stratified but in which recent nonwhite migrants and their progeny can come to have a genuine sense of belonging to Britain without having to disavow their 'ethnic' identities. The understanding of this is that it requires the possibility of significant inter-generational social mobility in which higher education has a critical role. A more specific concern is about Pakistani young men. While Pakistani young men are not demographically underrepresented in higher education and are more likely to go to university than their white peers, they are also over-represented amongst those with no or low qualifications and there are some indications that this latter group are not making, perhaps even not trying to make the progress that their female peers exhibit. 
The article is in three parts. First, the empirical case will be presented about the scale and character of ethnic minority representation in higher education. Second, some explanations will be given for why this is the case. Here, some answers will be offered which are thought to be true, some based on evidence and some speculative. The final part will consider whether the concepts of cultural and social capital are of any assistance in organizing and improving some aspects of what are believed to be the answers. In this, the order is reversed of a recent related inquiry, which argues for the importance of identifying the components of social capital theory and then tests it against the available facts about Pakistanis and other minorities and education, so as to work out which aspects of the theory are true or false (Abbas, unpublished). The interest here is not in evaluating social capital theory per se but in answering the question above.

\section{Part 1: Ethnic Minorities in Higher Education ${ }^{1}$}

Contrary to the claims of most commentators at the time, when admissions to higher education began to be 'ethnically monitored' in 1990, they did not reveal an underrepresentation of ethnic minorities (Modood, 1993). Moreover, all minority groups, with the possible exception of the Caribbeans, have increased their share of admissions since then. Ethnic minorities as a whole are about 50 per cent more successful in achieving university entry than their white peers. There are, however, important differences amongst and within groups.

More than twice the proportion of 18-24 year old Africans, Chinese, Asian-Others and Indians enter university than do whites, and no minority group is underrepresented as such, as can be seen in Table 1 below. In some cases, there are significant gender differences. For example, Caribbean men and Bangladeshi women are underrepresented, although in the latter case there is a trend towards equal/over representation. Otherwise, it is only the whites that are under-represented in both genders. The trend

Table 1 Domiciled First Year Full-Time and Part-Time Students, 1997-98

\begin{tabular}{lllll}
\hline & Percentage in & $\begin{array}{l}\text { Percentage 18-24 } \\
\text { year olds in } \\
\text { higher education }\end{array}$ & $\begin{array}{l}\text { Percentage of } \\
18-24 \text { year } \\
\text { olds in Great } \\
\text { Britain }\end{array}$ & $\begin{array}{l}\text { 18-24s gender } \\
\text { balance in } \\
\text { higher education } \\
\text { (m-f) }\end{array}$ \\
\hline White & 84.9 & 85.2 & 92.0 & $48^{*}-52^{*}$ \\
Indian & 4.1 & 4.7 & 2.0 & $51-49$ \\
Pakistani & 2.5 & 2.7 & 1.8 & $56-44$ \\
Bangladeshi & 0.7 & 0.7 & 0.7 & $58-42^{*}$ \\
Chinese & 0.9 & 1.0 & 0.4 & $50-50$ \\
Asian-other & 1.2 & 1.2 & 0.4 & $52-48$ \\
Africans & 2.1 & 1.4 & 0.6 & $48-52$ \\
Caribbeans & 1.3 & 1.0 & 0.9 & $40^{*}-60$ \\
Black-others & 0.6 & 0.5 & 0.7 & $38^{*}-62$ \\
\hline
\end{tabular}

Note: *denotes under-representation

Source: Higher Education Statistics Agency, 1991; Census and LFS, 1999-2000 
analysis in Table 2 shows that between 1994-99, at a time when the number of entrants to higher education rose by more than 20 per cent, most minority groups increased by 40-85 per cent (but the Black Caribbean numbers, grew by just under 20 per cent). In short, minority groups, with the exception of Caribbean men, are on different points of an escalator, all moving upwards relative to whites and in fact some groups exceeded the Government's target of 50 per cent participation by age 30 some years ago (Connor, Tyers, Modood \& Hillage, 2004, pp. 43, 150).

There are also important differences within institutions and subjects. While some minorities are very well represented in some competitive subjects, they are (with the exception of the Chinese) still generally more likely to be in the less prestigious, less well-resourced post-1992 universities. This is especially true of Caribbeans (Modood \& Acland, 1998) who are also more likely to be mature students (Owen, Green, Pitcher \& Maguire, 2000; Pathak, 2000) (more than half of Caribbean women students are over 25 years old) and part-time students (Owen et al., 2000), all factors, which have implications for career prospects. A-level scores, subject preferences, preference for local institutions, type of school or college attended are all factors that explain the concentration of ethnic minority groups (again, with the exception of the Chinese) in the new universities. Nevertheless, a recent analysis shows that even accounting for these factors, there is a clear institutional effect (Shiner \& Modood, 2002). Comparing similarly qualified candidates and controlling for factors such as public schools, gender and so on, new (post-1992) universities respond more positively than old universities to non-white applicants and, within this sector, Chinese, Bangladeshi and Indian candidates appear to be favoured over whites. When applying to old universities, however, there is strong evidence that minority candidates face an ethnic penalty. Institutions within this sector are most likely to select white and, to a lesser extent, Chinese candidates from among a group of similarly qualified applicants. Given the much larger proportion of applications from ethnic minority groups, although ethnic minority applicants may be admitted to old universities in reasonable numbers, they generally have to perform better than do their white peers in order to secure a place. As the type of institution from which you graduate can make a big difference to your career prospects, this

Table 2 Percentages of Home Accepted Applicants to Degree Courses

\begin{tabular}{lccccccc}
\hline Ethnic origin & 1994 & 1995 & 1996 & 1997 & 1998 & 1999 & $\begin{array}{l}\text { \% change } \\
1994-99\end{array}$ \\
\hline White & 85.37 & 84.27 & 82.59 & 81.17 & 79.64 & 79.3 & 12.64 \\
Black & 0.95 & 0.97 & 0.97 & 0.99 & 0.95 & 0.94 & 19.88 \\
$\quad$ Caribbean & & & & & & & \\
Black African & 1.31 & 1.48 & 1.55 & 1.54 & 1.45 & 1.51 & 40.41 \\
Indian & 3.23 & 3.33 & 3.6 & 3.67 & 3.92 & 4.13 & 55.01 \\
Pakistani & 1.58 & 1.77 & 2 & 1.98 & 2.11 & 2.17 & 66.39 \\
Bangladeshi & 0.43 & 0.52 & 0.57 & 0.55 & 0.6 & 0.66 & 85.03 \\
Chinese & 0.76 & 0.81 & 0.88 & 0.88 & 0.9 & 0.94 & 50.89 \\
Total & 228,685 & 240,710 & 246,503 & 276,503 & 272,340 & 277,340 & \\
\hline
\end{tabular}

Source: Table 5.2, UCAS Statistical Bulletin on Widening Participation, 2000, p. 13 
bias makes older universities complicit in an institutional discrimination that hinders and slows down the dismantling of ethnic stratification. ${ }^{2}$

\section{Part 2: Some Possible Causes}

\section{Class}

For most British sociologists, class is the best explanation of educational outcomes. For example, Goldthorpe's theory of social mobility holds that individuals of differing class origins will differ in the use they make of available educational opportunities. Those from more advantaged class backgrounds, pursuing strategies from above, will exploit such opportunities more fully than will those from less advantaged backgrounds, pursuing strategies from below, and with the backing of superior resources (Goldthorpe, 2003; also 2000).

Class, however it is defined and operationalized, is an important part of the interest here. It will, however, be far from the whole story. Some of these other factors may be to do with proximity to good schools or aspects of individual biographies, including the interests and efforts of one's parents. In the case of minorities, there will be factors distinctive to particular minorities or to the condition of being a minority in Britain today, such as racialized exclusion. Some of these distinctive factors will work to reinforce or deepen class effects; others to lessen them. Or, to put it another way, some of these factors will work to worsen the socio-economic position of a minority group relative to the rest of society; other factors may have the opposite effect. For example, a study of young people which systematically controlled for social class attributes found that the likelihood of achieving 5 GCSEs at $\mathrm{A}^{*}-\mathrm{C}$ for Pakistanis and Indians (analysed separately) was 10 per cent higher than their white social class peers; for black Caribbeans it was 8 per cent less (Bradley \& Taylor, 2004). Ethnic group membership, then, can mitigate or exacerbate class disadvantage; and this may, of course, change with the circumstances.

Again, while it is generally true that the minority groups with the largest proportions in higher education, especially in pre-1992 universities, have a more middle-class profile than the other minorities, it is not invariate; Pakistanis have a worse occupational earnings and household profile than the Caribbeans but a larger proportion in higher education. Moreover, the undiluted class model is no help in explaining why the minorities (all of whom have or until recently had a (much) worse class profile than whites) perform better than whites. This can be seen from Table 3, which shows university entrants of 1998 by ethnicity, gender and parental social class. It shows an absence of gender difference, but that class is a major factor: in nearly every group, the offspring from non-manual parents exceed, sometimes by a large margin, those from manual parents. This is particularly the case amongst whites, but is also of considerable magnitude amongst Africans and Caribbeans. But it has much less significance for Indians and Chinese, groups in which entrants are almost equally likely to come from non-manual as from other backgrounds, including unemployment. The conventional class analysis does not 
Table 3 UCAS 1998 Entrants by Ethnicity, Gender and Parental Social Class

\begin{tabular}{|c|c|c|c|c|c|c|c|c|c|c|c|c|c|c|}
\hline & \multicolumn{2}{|c|}{ White } & \multicolumn{2}{|c|}{ Chinese } & \multicolumn{2}{|c|}{ Indian } & \multicolumn{2}{|c|}{ Pakistani } & \multicolumn{2}{|c|}{ Bangladeshi } & \multicolumn{2}{|c|}{ Afro-Caribbean* } & \multicolumn{2}{|c|}{ Black African } \\
\hline & $\mathrm{M}$ & $\mathrm{F}$ & M & $\mathrm{F}$ & M & $\mathrm{F}$ & $\mathrm{M}$ & $\mathrm{F}$ & $\mathrm{M}$ & $\mathrm{F}$ & $\mathrm{M}$ & $\mathrm{F}$ & M & $\mathrm{F}$ \\
\hline Non-manual & 67.1 & 67.4 & 52.5 & 52.7 & 48.5 & 48.4 & 36.5 & 36.1 & 36.3 & 35.8 & 52.1 & 56.4 & 51.5 & 54.8 \\
\hline Manual & 25.2 & 24.6 & 33.7 & 33.7 & 39.5 & 39.7 & 39.7 & 38.2 & 39.2 & 38.9 & 26.9 & 24.4 & 20.5 & 19.3 \\
\hline Unknown** & 7.7 & 8.0 & 13.8 & 13.6 & 12.1 & 12.0 & 23.8 & 25.8 & 24.5 & 25.3 & 21.0 & 19.2 & 28.1 & 25.9 \\
\hline
\end{tabular}

Notes: *Includes 'Black-Caribbeans' and 'Black-others'

**The vast majority of parents whose Social Class UCCA classifies as unknown appear to have been unemployed Source: Ballard, 1999 
hold at all for Pakistanis and Bangladeshis, amongst whom households headed by a manual or unemployed worker supply nearly two-thirds of the entrants.

To some extent, it can be said this was because the South Asian and Chinese entrants' parental social class and educational capital was better than that suggested by their parents' occupations, for their occupational levels were depressed by migration effects and discrimination in the labour market. Due to this racial discrimination migrants often suffered a downward social mobility on entry into Britain (Modood et al., 1997, pp. 141-142). The only jobs open to them were often below their qualification levels and below the social class level they enjoyed before migration. This meant that not only did many value education more than their white workmates but saw it as part of the process of reversing the initial downward mobility, especially in the lives of their children. Certainly, if we look at the qualification levels of the migrants at the time of migration, this argument that migrants' occupational class in Britain is not reflective of their true class and hence of their attitudes to education seems to have some plausibility (Modood et al., 1997, pp. 68-69). It is particularly plausible in the case of the African Asians and perhaps also the Indians, but less so with other groups. In any case, class analysis by itself, even after taking initial downward mobility into account, is incomplete without acknowledging the economic motivation of migrants, the desire to better themselves and especially the prospects of their children.

Even more fundamentally, if the definition of class by Savage et al. (2003, p. 7) (quoted previously) is accepted, then, as will be explained below, this categorization of people by the possession of similar resources can be a characteristic of ethnicity. That is to say, it can vary across ethnic groups within the same occupational/ income classes. Hence, here ethnicity seems to cut across class, possibly even to constitute class in some ways because ethnicity can mean resources.

\section{Racism}

Another line of explanation that has prominence in the literature points to the possible role of racism. This could, for example, consist of factors influencing how teachers treat different groups, to policies which indirectly discriminate (for example, by placing more pupils from certain ethnic groups in lower sets) and to the general ways in which groups of people in British society are perceived and treated. Each of these can have an effect on the groups in question, who may then react in certain kinds of ways, most notably by being demotivated or confrontational. This may also lead to social stereotyping on the part of educators and university admissions tutors, creating a vicious cycle. This line of explanation seems to work better with blacks than Asians. For example, data from local education authorities suggests that at the beginning of schooling, and at the time of the first national tests at age 7 , the difference between Caribbeans and whites is relatively slight, and sometimes in the favour of the Caribbeans. It is the South Asian children, often coming from homes in which English, if spoken at home, is a second or third language, that begin their school careers with low averages (this was even more so when those who are in higher education today would have started schooling). But while in secondary 
school the Asians slowly catch up, and in the case of some groups, overtake the whites, the Caribbeans' average steadily drops behind that of the national average (Berthoud et al., 2000; Gillborn \& Mirza, 2000; Owen et al., 2000; Richardson \& Wood, 1999).

Perhaps then there is more racism against blacks than Asians, especially Indians. The evidence, however, points the other way. For example, the PSI Fourth Survey found that most people in 1994 believed that of all ethnic, racial and religious hostility, that against Asians, especially Asian Muslims, is the greatest; this is likely to have increased post-9/11. Indians, clearly a successful group, are not immune from this hostility. The causes of the hostility may lie in perceptions of Pakistanis or (Asian) Muslims but the effects are visited on Asians more generally, as turban wearing Sikh men who have been abused as 'Islamic terrorists' could testify. Even within the specific context of schooling South Asians experience more frequent and more violent racial harassment from other pupils than the Caribbeans (Gillborn, 1998; Virdee, Modood \& Newburn, 2000). Therefore, an appeal to racism by itself may have little explanatory value without considering how a target group reacts to exclusion. Bullying is suppose to put students off schools and academic work but as we have seen Asians make progress and they have very high staying-on rates beyond the period of compulsory schooling (Modood et al., 1997).

\section{Ethnic Strategies from Below}

Perceptions of racism and biases in the labour market may contribute to these high staying-on rates, but when Asians who stay on are questioned they give positive reasons (especially the desire to go to university) rather than negative reasons (such as the need to avoid unemployment) (Basit, 1997; Hagell \& Shaw, 1996). Even cultures that until recently might have been portrayed as opposed to the higher education of and employment of women seem to be producing growing cohorts of highly motivated young women (Ahmad, Modood \& Lissenburgh, 2003).

So, ethnic minorities in general and Asians in particular seem to have a strong drive for qualifications. This 'motor' cannot be explained by short-term or Britain-only class analysis, although it is partly explained (more in the case of some groups rather than others) by long-term class analysis which enquires into pre-migration class locations. However, it should be noted that this raises questions of commensurability and fit between what class means in contemporary Britain and what it means in radically different societies and economies. For example, how are Punjabi peasants who own very little individually but through an extended family own a small farm to be compared to hospital porters in London with higher levels of personal consumption and leisure time but little property?

Ultimately, a wider sociological framework will be necessary in order to answer the question about ethnic minority entry into higher education in a way that connects with wider explanations. Racism, cultural adaptation, deprived neighbourhoods are amongst the features that cannot be ignored. There are indeed various sorts of disadvantages that can be stacked up and they offer explanatory assistance if it is necessary to explain failure. But given that success is being explained here, all these factors serve only to compound the problem. 
So, what is the source of this 'motor', this ability to drive through large-scale, sociologically corroborated disadvantages? Thinking particularly of the South Asians and Chinese, it can be speculated that the answer might lie in their families and communities. For instance, through the following causal sequence:

- parents, other significant relatives and community members share some general, but durable, ambitions to achieve upward mobility for themselves and especially for their children and believe that (higher) education is important in achieving those ambitions, and so prioritize the acquisition of (higher) education;

- they are successfully able to convey this view to the children who to a large degree internalize it and even where they may not fully share it they develop ambitions and priorities that are consistent with those of their parents;

- the parents have enough authority and power over their children, suitably reinforced by significant relatives and other community members, to ensure that the ambition is not ephemeral or fantastic but the children do whatever is necessary at a particular stage for its progressive realization.

Of course not all Asians (even in terms of groups, let alone within groups) are academically successful, but explaining success will be a major theoretical outcome-given the absence of suitable explanatory strategies-and perhaps, although there are political pitfalls here, explaining the successful may help to throw scientific light on the cases of the unsuccessful. Moreover, that may be the basis for an understanding that could assist to reverse the circumstances of the unsuccessful.

The proposed triadic 'motor' here is consistent with the data presented so far and hopefully can help to explain why socio-economic disadvantage and racism, which are indisputably real forces, do not have the effects that sociological research would have predicted. One new and final piece of data can be offered that might support the line being taken here. Table 4 is from a recent survey of Year 13 students, in which respondents had to mark statements on a $1-5$ scale ( $5=$ strongly applies), and some answers are presented in aggregate form. Besides confirming ethnic minority respondents in the sample, relative to whites, were more likely to have had few family members who had been to university, it reveals that they nevertheless had received more encouragement from family to go to university. Most counter-intuitive of all, they (except the black Caribbeans) were more likely to say, that it 'had always been assumed they would go to HE'. As this counter-intuition neatly matches the counter-intuition of the fact of ethnic minority over-representation, it is not unreasonable to suppose that the two are linked.

Finally, there is a brief look to see if there is anything in the cultural and social capital literature that might help with this line of thinking.

\section{Part 3: Cultural and Social Capital}

Some contributions to these topics will be reviewed. A full picture of the views of any particular author or school will not be offered, but it will be stated why it is thought that a particular body of work may or may not be useful to the present inquiry. 
Table 4 Factors Affecting Decisions by Potential Higher Education Entrants (Year 13) to go on to Higher Education by Ethnic Group (Mean Scores)

\begin{tabular}{|c|c|c|c|c|c|c|c|}
\hline $\begin{array}{l}\text { Issues affecting } \\
\text { decision }\end{array}$ & $\begin{array}{l}\text { Black } \\
\text { African }\end{array}$ & $\begin{array}{l}\text { Black } \\
\text { Caribbean/ } \\
\text { other }\end{array}$ & $\begin{array}{l}\text { Pakistani/ } \\
\text { Bangladeshi }\end{array}$ & Indian & $\begin{array}{l}\text { Chinese/ } \\
\text { Asian } \\
\text { other }\end{array}$ & $\begin{array}{l}\text { All } \\
\text { minority } \\
\text { groups }\end{array}$ & White \\
\hline $\begin{array}{l}\text { Few family been to } \\
\text { university }\end{array}$ & 2.8 & 2.9 & 2.8 & 3.1 & 3.0 & 3.0 & 2.5 \\
\hline $\begin{array}{l}\text { Encouragement } \\
\text { from family }\end{array}$ & 4.0 & 4.0 & 4.0 & 4.0 & 3.8 & 4.0 & 3.4 \\
\hline $\begin{array}{l}\text { Always assumed } \\
\text { would go to } \\
\text { higher education }\end{array}$ & 4.0 & 3.2 & 4.0 & 4.1 & 3.9 & 3.9 & 3.1 \\
\hline $\begin{array}{l}\text { Base } \mathrm{N}=100 \% \\
\text { min. respondents }\end{array}$ & 94 & 68 & 117 & 166 & 68 & 567 & 217 \\
\hline
\end{tabular}

Note: Scores range from one to five, where one represents 'Does not apply/no effect' to five 'Applies strongly/big effect' Source: Connor et al. (2004) 


\section{Bourdieu and Cultural Capital}

Bourdieu's initial ideas about cultural capital seem to suit this article very well: they were developed in relation to an inquiry about the non-random distribution of educational qualifications and he speaks about investment strategies employed by different kinds of families (Bourdieu, 1997). Moreover, a central point is that there are different forms of capital so that it is possible for a family to be poor in one form and rich in another, which fits with the case of socio-economically disadvantaged Pakistani households having another kind of resource from which they can produce graduates. The view that familial norms are not irrelevant to the production of socio-economic advantages and disadvantages is also highly relevant. Moreover, Bourdieu's work offers a theoretical framework for making the links to the wider social structure, power and ideology.

On the negative side, it has to be said that he has very little to say about ethnicity and indeed assumes a cultural homogeneity (at least within classes). His major limitation, however, is that he is asking about how the dominant class reproduces its domination, whereas the current study is asking how subordinate groups can achieve upward mobility. His interest is in how those with financial capital can convert it into educational qualifications and then back again. But the starting point here are groups with little economic capital and Bourdieu's framework does not seem to be suitable for examining how such groups can generate social mobility for significant numbers of their members.

Bourdieu's work is reminiscent of the American anthropologist, Ogbu, who has also tried to create a theoretical framework to connect society-wide socio-economic structures (what he calls 'the system') with the different trajectories and dynamics of various minority groups (what he calls 'community forces') (Ogbu \& Simons, 1998). His fundamental distinctions revolve not around capital and class but about different kinds of minorities. He distinguishes between voluntary or immigrant minorities, such as the Cubans or Koreans in the USA, and involuntary or non-migrant minorities such as blacks, indigenous people and Mexicans in that country. This is an extremely important and powerful distinction, although it ought not to he treated too dichotomously for most non-white groups in Britain are a legacy of empire and their movement to Britain needs to be dually characterized as a migration across countries and simultaneously as a movement internal to a political-economic system. Ogbu shows how the distinction of voluntary/involuntary arises from 'the system' (which conquers/enslaves or permits migrants to settle) but has profound consequences for 'community forces'. For example, it is argued that 'voluntary minorities are less conflicted about accommodating to white society, so their role models include people who fully adopt white ways and language', while of such persons amongst involuntary minorities it is suspected that for them to have succeeded they probably have had to adopt white ways such as speaking standard English, which is seen as giving in to the white oppressor and abandoning their identity' (Ogbu \& Simons, 1998, p. 173). As Ogbu develops his theory with primary reference to school performance it is clear that his cultural-ecological 
approach, in some ways resembling Bourdieu's ideas of cultural capital and habitus, ${ }^{3}$ has something relevant to offer to the concerns here, as long as the voluntary-involuntary minorities distinction is not forcefully pressed.

\section{Putnam and Social Capital}

Robert Putnam is currently the name most associated with social capital (Putnam, $1995,2000)$. His interest is in asking about the healthy functioning of contemporary liberal-democratic societies and so, no less than Bourdieu, is some distance from the question about how some specific groups are able to achieve social mobility by means of education. Nevertheless, his work does carry ideas useful to this study, for example, his famous distinction between bonding, bridging and linking social capital: first bonding a distinctive group together, but the other side of the coin of that is that it separates the group from others, unless members of the group at the same time develop bridges to members outside the group; finally, a form of social capital most relevant to mobility is that which links people across classes to those in positions of power or influence (Putnam, 1995, 2000). This distinction seems to be prima facie relevant in distinguishing between those South Asian communities who have achieved upward mobility, such as say the Gujaratis of Leicester, and those who have not, such as Pakistanis of Bradford, perhaps because the latter, unlike the former, are strong in bonding capital but lack bridging and linking capital. Of course I do not mean to suggest, and one has to be careful to not suggest, that communities strong in bonding capital and weak in bridging capital are the sole cause of differential outcomes such as the positions of the those two communities. For that would ignore how exclusion and segregation in the northern cities and elsewhere has been shaped by white people's preferences as individuals, and the decisions of local councillors, not least in relation to public housing. Nevertheless, it seems to be possible to use Putnam's distinction between forms of social capital without 'blaming the victim'.

Another central contention of Putnam's is that participation in formal, voluntary organizations, regardless of the kind or quality of participation, is itself a decisive measure of all kinds of social goods, from crime-free neighbourhoods to better personal health and higher personal incomes. Although there was scepticism at first about the utility of this proposition for the current study, it was later noted that at least one study has found that 'the organizational involvement of both parents and children promotes school achievement' (Bankston \& Zhou, 2002, p. 311; Zhou \& Bankston, 1998).

\section{'Ethnicity as Social Capital' Studies in the USA}

There are a number of American empirical analyses that apply a concept of social capital to the study of ethnic groups (for a list see Bankston \& Zhou, 2002, p. 289). So far this body of work is virtually unknown in Britain, if citations are any indication. Broadly speaking, they seem to be in a stream, but correcting itself as it goes along by reference to findings, derived from James Coleman (for example, Coleman, 1988, 
1990; like Bourdieu, the interest was in explaining unequal scholastic outcomes), and perhaps initially intimated by the economist Glenn Loury in relation to the labour market position of African Americans (Loury, 1977). The empirical studies, while attempting to develop intermediate or grounded theory, do not slavishly follow any particular theorist or all aspects of the work of a useful theorist. For example, they assert the importance of the social in all kinds of ways, while Coleman attempted to explain the social in terms of an economic-psychological individualism. Again, Coleman believed that his work endorsed a certain moral conservatism on matters such as the importance of a non-working mother within a two-parent family for children's development, whereas the later studies on ethnicity give support to a broader range of positions. Moreover, Alejandro Portes, perhaps one of the first to use the ideas of social capital and network theory in relation to immigrant ethnicity is scathing about some of the hyperbolic and vacuous uses of the concept of social capital (he particularly has Putnam in mind) and highlights negative as well as positive outcomes of social capital (Portes, 1998).

Bankston and Zhou (2002) are also critical of some of the ways that social capital has been used. They make some important and apposite philosophical points:

... social capital, a ... metaphorical construction, does not consist of resources that are held by individuals or by groups but of processes of social interaction leading to constructive outcomes. Therefore, we argue that social capital is not located at any one level of analysis and that it emerges across different levels of analysis. The confusion over the meaning of this term, then, is a consequence of a metaphorical confusion of a substantive quantity (capital) and a process that takes place through stages (embedded, goal-directed relations). Locating and defining social capital is further complicated by the variability, contextuality, and conditionality of the process. Stages of social relations that lead to constructive outcomes for one group of people or in one situation may not lead to constructive outcomes for another group or in another situation. (Bankston \& Zhou, 2002, p. 286)

On their reading of the relevant literature, two particular dimensions of social capital seem to have emerged in research that are particularly relevant to the family: 'intergenerational closure' and 'norms enforcement' (Bankston \& Zhou, 2002, p. 287). The first is a specific case of the general interest, derived from Coleman, in 'dense associations' (Coleman, 1990), in the belief that the kind of relationships that lead to non-monetary exchanges and cooperative behaviour involve a high degree of trust, and this is likely to be fostered where individuals see themselves as similar, as sharing the same values, having frequent contact with each other and with each others' contacts and so on. In the case of families, 'intergenerational closure' is achieved where parents know the parents of their children's friends, so that the network of parents and the network of children involve many of the same families. Nevertheless, 'intergenerational closure' seems to set the bar too high; continuity of purpose and values across generations may be quite enough. There is a need to be careful of a general tendency to prefer dense and closed relationships in themselves, for as early as the work of Granovetter (1973), it was clear that for many purposes, such as acquiring information about employment opportunities, positive outcomes 
are more likely to flow from a set of wide and loose relationships rather than 'dense' ones. This is one of the advantages of Putnam's concepts of bridging and linking capital, requiring the analyst to broaden the range of relationships, beyond the obvious ones of bonding, that facilitate valuable social outcomes. Indeed, in at least one empirical analysis, it has been found that the high academic scores of Asian Americans are not due to close parent-child ties, for those ties were absent (Bankston \& Zhou, 2002, p. 310). As for 'norms enforcement', it is of course critical that if certain goals are dependent on focused effort, then the norms that inform those goals must not only be shared but must be enforced, otherwise they would only be vague aspirations or good intentions.

Therefore, the kind of ethnic capital of interest to this study seems to require three different stages or dimensions: relationships, norms and norms enforcement, although the kind of relationships, norms and norms enforcement that will lead to university entry may vary across group, time and place. Indeed, an erstwhile successful strategy may need to be changed as circumstances change. It is not, then, a competition between dense versus loose, but what might work for a particular group in specific circumstances. What kind of and how much of dense and what kind of and how much of loose? This of course would be highly relevant to current policy debates about segregation, disadvantage and social cohesion.

However, focusing on the question here, it does seem to be that this literature suggests an important triad: familial adult-child relationships, transmission of aspirations and attitudes and norms enforcement. This triad seems to be highly pertinent to speculative suggestions as to where to find the 'motor' of Asian academic success. This is not at all surprising for authors such as Zhou and Bankston, whose work considered groups, such as the Vietnamese, who arrived in the US poor, without pre-existing ethnic community networks to assist them and have achieved outstanding academic performance (Zhou, 1997; Zhou \& Bankston, 1998). Moreover, it should offer the opportunity to connect with other and wider social dimensions. For example, consider identity. People act (or try to act or fail to act) the way they do because it seems to them to be living an identity which they believe they have or aspire to have; certain behaviours make sense or do not make sense, become possible or 'impossible', easy or difficult, worth making sacrifices for and so on if certain identities-like ethnic or minority identities - are strongly held. The above triad may cluster with other beliefs and behaviours that give some Asians a sense of who they are, their location in the world and what is expected of them. This can be a fruitful inquiry even if ethnic essentialism is rejected (and we are careful to not impose too restricted a purview of which adult-children relationships are important) for the self-concept that 'We as a group are striving and struggling to achieve higher status and prosperity, respectability, in this land where the dice is loaded against us but success is achievable, and you have to play your part' can be bound up with say, being Indian in Britain, even if it is only contingently and not essentially so. The transmission of a normative identity will, be more important than say, parental-child 'quality-time', talking together about schoolwork or friendships, or any specific skills and knowledge transfer. Indeed, Asian migrant parents may have little relevant economic-human capital to 
transmit but subsequent human capital acquisition by their children may depend upon parent-child transmission of norms-laden and goals-directing identities. The motivational power of identity does not necessarily need closed, dense communities and is more at the heart of ethnic minority social/cultural capital than, say, residential concentration, mutual self-help or community institutions.

If identity is too intangible an example, it is clear that the triad must connect with specific measurable behaviours, for example, making children do academic homework. Moreover, 'norms enforcement' cannot just mean discipline, it must extend to also include the provision of resources (like books and tutors) that enable children to proceed on the appropriate normative path. This is an extremely fruitful line of inquiry, but the first step will have to be the creation of data because at present (because researchers have not asked the appropriate questions) there is no data (by ethnicity) on what periods of academic work, not necessarily just set by the school, are done outside school hours, let alone what proportions of disposable income are spent by households on children's education.

Another way of going beyond the family is by looking at the locales in which the families under study are based and in ways that the neighbourhoods contribute to or impede in the realization of the families' academic goals. Drawing on her study of Chinatown in New York and elaborating on the role that that community organizations play there in assisting upward social mobility, Min Zhou makes a distinction between an ethnic/racial ghetto and enclave (Zhou, 1992, 2004, forthcoming). Both are typified by high levels of ethnic group segregation and an absence af highly paid jobs, but an enclave, unlike a ghetto, is likely to be economically dynamic and aspirant, allow cross-class relationships, thus enhancing information channels, job opportunities and models of academic and economic success, all of which reinforce the promise of upward mobility missing in a ghetto. This is a distinction that can be connected with Ogbu's approach as described above, as well as Putnam's emphasis on the importance of bridging and linking, as well as bonding capitals. It is, therefore, another fruitful distinction to explore even though the levels of ethnic segregation in Britain are much lower than those in the US.

\section{Conclusion}

In the US literature examined here, the Bourdieuian distinction between cultural capital, which is acquired through the family, and social capital as benefits mediated through social relations, is not maintained; the former is indistinguishably incorporated within the latter. This suits the purposes of this study, for if the question is what role does the ethnic background play, the family is integral to that background but clearly does not exhaust the contribution of ethnicity. Hence perhaps the appropriate term should be 'cultural-social capital'; or perhaps, 'ethnic capital' (modified from 'ethnicity as social capital' in Zhou, 2004, forthcoming). It perhaps runs the risk of reification and suggests that a certain ethnic group (for example, Pakistanis) are a static, homogeneous, neatly bounded group; features not being implied but denied, if less radically than in the current social science orthodoxy, and which can be 
countered in specific empirical analyses. On the other hand, it has the advantage of flagging up diversity, namely that the capital in question will vary across ethnic groups, not just in degree but also in kind; it also suggests a certain kind of marginality and exclusion which is not fully explicable in class terms. It has the further advantage that it limits the position that has to be defended: some or all of the uses of 'social capital' may be separated out from a particular use that relates to some ethnic groups.

The article leaves open for another discussion whether the concept of cultural capital will resume relevance if the picture is widened to consider why ethnic minorities experience an ethnic penalty in relation to entry into prestigious universities and the labour market returns they receive for their university degrees-that is to say to explain why these groups are not doing even better than they are doing. The study will conclude by considering the suggestion that the reason the power of established cultural capital does not seem to deter some ethnic minorities from (higher) education is perhaps because they are outside the parameters of 'white' cultural capital in its entirety, (i.e. unlike the white working class, they do not really pick up or understand the cues ${ }^{4}$ ). This is quite mistaken (although it might have been true at a very early point in the migration process). Leaving aside the perverse implication that ethnic minorities will only start behaving in a disadvantaged way after they are socially included, there is a need to divide 'white cultural capital' into at least two. First, there is working-class, popular culture, often American-derived, especially in relation to youth culture, of Hollywood, soap-operas, music, clothes fashion, celebrities, football, pubs, clubs and binge-drinking. It is a dominant culture whose cues British blacks have not only picked up but in which they have come to be a leading-edge presence, quite remarkable for a group that is less than 2 per cent of the population, stigmatized and economically disadvantaged (Hall, 1998; Modood, 1999). Asian parents no doubt have little credence in this domain and try to limit their children's exposure to it.

Second, there is a middle-class culture, meaning not just 'high culture' and leisure pursuits but, more importantly, including high social status conferring occupations and tending more towards respectability than celebrity and hedonistic consumption, and entry into which nearly always requires a good university degree. This is the dominant culture that non-white ethnic minority parents would like their children to integrate into, as so many other groups have done before, most conspicuously the Jews. So, it is not a question of missing cues but of a determined effort to avoid one dominant culture and steer towards another. Of course, this still leaves open the question why in relation to universities many minority ethnic young people fail to think 'that's not meant for me' in the way that is supposed to be characteristic of many white working-class young people. This article has offered a series of suggestions, ranging from (in the absence of suitable data) speculations to critically and syncretically learn from the American literature which, while much in advance of its British counterpart, will certainly need to be appropriately reworked to answer British questions.

At present Asian university entrants are typically children of migrants; they are 'second generation' (Connor, Tyers, Modood \& Hillage, 2004). In due course, however, this generation, having lifted itself into the middle class, will produce a 
generation that will benefit from some of the standard advantages of being born middle class, including the acquisition of cultural capital that assists entry into prestigious universities and professional and managerial jobs. We would then be studying a different phenomenon. The interest in this article has been in what kind of capital, if any, can explain the upward educational mobility of predominantly working class, outsider, ethnic groups. ${ }^{5}$

\section{Acknowledgements}

The author is grateful for the support of the Leverhulme Trust for its funding of the Migration and Ethnicity Research Programme at the University of Bristol and University College London. This article is part of the preliminary and early work within the Programme project on Gender, Social Capital and Differential Outcomes. Grateful thanks are due to Gurchathen Sanghera for some research assistance. For more details see http://www.bris.ac.uk/Depts/Sociology/leverhulme

\section{Notes}

[1] For fuller evidential support for this section, see Modood et al., 1997, chapters 3 and 4; Modood, 2003.

[2] It should be borne in mind, however, that some ethnic minority groups have a disproportionately large number of their 18-24 year olds in higher education, and therefore are digging deeper into the natural talent available in that age group. Hence, it is not in itself surprising that a larger proportion of their applicants enter institutions that require lower A-level entry scores. If like were compared with like, the peers of some who enter these universities are whites who are absent from higher education.

[3] It has been suggested that even if Bourdieu's concept of cultural capital is not helpful to answering the question that has been posed in this article, nevertheless his concepts of habitus and field could be (May, 1999). Such concepts, however, are organized to analyse class divisions. Stripped of that analytical purpose, they become less distinctive. Similar ideas about the importance of pre-existing social contexts and on-going activities are available from other sources. In my case (Modood, 1984), I have learnt from Wittgenstein's ideas of 'language game' and 'meaning lies in use' (Wittgenstein, 1968) and Oakeshott's theories of 'modes of experience' (Oakeshott, 1933), 'tradition' and 'practical knowledge' (Oakeshott, 1962), and Collingwood on 'forms of experience' (Collingwood, 1924).

[4] I am grateful to Mike Savage for raising this point with me.

[5] After writing this article I discovered Laughlo 2000, which, while based on Norwegian data, is closely allied to the argument of this article.

\section{References}

Abbas, T. (2003, November 6). Ethnicity and social capital: bonding, bridging and linking in the education of a British Pakistani community. Leverhulme Programme on Migration and Citizenship Seminar Series, University of Bristol, Bristol.

Ahmad, F., Modood, T., \& Lissenburgh, S. (2003). South Asian women and employment in Britain: The interaction of gender and ethnicity. London: Policy Studies Institute. 
Ballard, R. (1996). The Pakistanis: Stability and introspection. In C. Peach (Ed.), Ethnicity in the 1991 Census. Volume 2. The ethnic minority populations of Britain. London: HMSO.

Ballard, R. (1999). Socio-economic and educational achievements of ethnic minorities. Unpublished paper submitted to the Commission on the Future of Multi-Ethnic Britain. London: The Runnymede Trust.

Baukston, C. L., III \& Zhou, M. (2002). Social capital as process: the meaning and problems of a theoretical metaphor. Sociological Inquiry, 72(2), 285-317.

Basit, T. N. (1997). Eastern values; Western milieu: Identities and aspirations of adolescent British Muslim girls. Aldershot: Ashgate.

Berthoud, R., Taylor, M., Burton, J., with contributions by Modood, T., Buck, N., \& Booth, A. (2000). Comparing the transition from school to work among young people from different ethnic groups. A feasibility study for the Department of Education and Employment. Colchester: Institute for Social and Economic Research, University of Essex.

Bourdieu, P. (1997). The forms of social capital. In A. H. Halsey, P. Brown \& A. S. Wells (Eds.), Education, culture, economy, society (pp. 46-58) Oxford: Oxford University Press. [First published in Richardson, J. E. (Ed.) (1986). Handbook of Theory for Research in the Sociology of Education. Westport, CT: Greenwood Press].

Bradley, S., \& Taylor, J. (2004). Ethnicity, educational attainment and the transition from school. The Manchester School, 72(3), 317-346.

Coleman, J. S. (1988). Social capital in the creation of human capital. American Journal of Sociology, 94, S95-S120.

Coleman, J. S. (1990). Foundations of social theory. Cambridge, MA: The Belknap Press.

Collingwood, T. (1924). Speculum mentis. Oxford: Oxford University Press.

Connor, H., Tyers, C., Modood, T., \& Hillage, J. (2004). Why the difference? A closer look at higher education minority ethnic students and graduates. Research Report 532. London: Department of Education and Skills.

Fenton, S. (1999). Ethnicity: Racism, class and culture. Basingstoke and London: Macmillan.

Fenton, S. (2003). Ethnicity. Cambridge: Polity Press.

Gillborn, D. (1998). Race and ethnicity in compulsory schooling. In T. Modood \& T. Acland (Eds.), Race and Higher Education. London: Policy Studies Institute.

Gillborn, D., \& Mirza, H. (2000). Educational inequality: Mapping race, class and gender, a synthesis of research evidence. London: Office for Standards in Education.

Goldthrope, J. (2000). On sociology. Oxford: Oxford University Press.

Goldthrope, J. (2003, April). 'Outline of a Theory of Social Mobility' Revisited: The Increasingly Problematic Role of Education. Conference in honour of Professor Tore Lindbekk, Trondheim.

Granovetter, M. S. (1973). The strength of weak ties. American Journal of Sociology, 78, 1360-1380.

Hagell, A., \& Shaw, C. (1996). Opportunity and disadvantage at age 16. London: Policy Studies Institute.

Hall, S. (1998). Aspiration and attitude... reflections on black Britain in the nineties. New Formations, [Special Issue] Frontlines/Backyards, 33, Spring.

Laughlo, J. (2000). Social capital trumping class and cultural capital? Engagement with school among immigrant youth. In S. Baron, J. Field \& T. Schuller (Eds.), Social capital: Critical perspectives. Oxford: Clarendon Press.

Loury, G. (1977). A dynamic theory of racial income differences. In P. A. Wallace \& A. Le Mund (Eds.), Women, minorities, and employment discrimination. Lexington: Lexington Books.

May, S. (Ed.) (1999). Critical multiculturalism and cultural difference: Avoiding essentialism. In S. May (Ed.), Critical multiculturalism: Rethinking multicultural and antiracist education. London: Falmer Press.

Modood, T. (1984). R. G. Collingwood, M. J. Oakeshott and the idea of a philosophical culture. Unpublished $\mathrm{PhD}$ thesis, University College, Swansea, University of Wales. 
Modood, T. (1993). The number of ethnic minority students in British higher education. Oxford Review of Education, 19(2), June, 167-182.

Madood, T. (1999). New forms of Britishness: post-immigration ethnicity and hybridity in Britain. In R. Lentin (Ed.) The expanding nation: Towards a multi-ethnic Ireland. Trinity College Dublin; reproduced in Sackmann, R., Peters, B., \& Faist, T. (Eds.) (2003). Identity and Integration. Migrants in Western Europe. Aldershot: Ashgate.

Modood, T. (2003). Ethnic differentials in educational performance. In D. Mason (Ed.), Explaining ethnic differences. Bristol: ESRC and The Policy Press.

Modood, T., \& Acland, T. (1998). (Eds.), Race and higher education. London: Policy Studies Institute.

Modood, T., Berthoud, R., Lakey, J., Nazroo, J., Smith, P., Virdee, S., \& Beishon, S. (1997). Ethnic minorities in Britain: Diversity and disadvantage. London: Policy Studies Institute.

Oakeshott, M. (1933). Experience and its modes. Cambridge: Cambridge University Press.

Oakeshott, M. (1962). Rationalism in politics and other essays. London: Methuen.

Ogbu, J. U., \& Simons, H. D. (1998). Voluntary and involuntary minorities: a cultural-ecological theory of school performance with some implications for education. Anthropology and Education Quarterly, 29(2), 155-188.

Owen, D., Green, A., Pitcher, I., \& Maguire, M. (2000). Minority ethnic participation and achievements in education, training and the labour market. London: Department for Education and Employment.

Pathak, S. (2000). Race research for the future: ethnicity in education, training and the labour market. Research Topic Paper. London: Department of Education and Employment.

Portes, A. (1998). Social capital: Its origins and applications in modern sociology. Annual Review of Sociology, 24, 1-24.

Putnam, R. (1995). Bowling alone: American's declining social capital. Journal of Democracy, 6(1), $64-78$.

Putnam, R. (2000). Bowling alone: The collapse and revival of American community. New York: Simon Schuster.

Reay, D. (2004). 'It's all becoming a habitus': beyond the habitual use of habitus in educational research. British Journal of Sociology of Education [Special Issue on Pierre Bourdieu's Sociology of Education], 25(4), 431-444.

Richardson, R., \& Wood, A. (1999). Inclusive schools, inclusive society: Race and identity on the agenda. Trentham Books.

Savage, M., Warde, A., \& Devine, F. (2004, January). Capitals, assets and resources: Some critical issues. Cultural Capital and Social Exclusion Workshop, Oxford.

Shiner, M., \& Modood, T. (2002). Help or hindrance? Higher education and the route to ethnic equality. British Journal of Sociology of Education, 23(2), 209-230.

Virdee, S., Modood, T., \& Newburn, T. (2000). Understanding racial harassment in school. A Project Report to the ESRC.

Wallman, S. (1979). Ethnicity at work. London: Macmillan.

Werbner, P. (1990a). The migration process. Oxford: Berg.

Werbner, P. (1990b). Renewing the industrial past: British Pakistani entrepreneurship in Manchester. Migration, 8, 7-39.

Wittgenstein, L. (1968). Philosophical investigations (G.E.M. Anscombe, Trans.). Oxford: Blackwell.

Zhou, M. (1992). Chinatown: The socioeconomic potential of an urban enclave. Philadelphia: Temple University Press.

Zhou, M. (1997). Growing up American: the challenge confronting immigrant children and children of immigrants. Annual Review of Sociology, 23, 63-95.

Zhou, M. (forthcoming, 2004-5). Ethnicity as social capital: community-based institutions and embedded networks of social relations. In G. Loury, T. Modood \& S. Teles (Eds.), Ethnicity, social mobility and public policy in the US and UK. Cambridge: Cambridge University Press.

Zhou, M., \& Bankston, C. L., III (1998). Growing up American: How Vietnamese children adapt to life in the United States. New York: Russell Sage Foundation. 